\title{
Microarray Expression Profile of Circular RNAs in Peripheral Blood Mononuclear Cells from Rheumatoid Arthritis Patients
}

\author{
Qingqing Ouyang ${ }^{\mathrm{a}}$ Jing Wu $\mathrm{Wh}^{\mathrm{a}}$ Zhenlan Jiang ${ }^{\mathrm{a}}$ Jinjun Zhao ${ }^{\mathrm{a}}$ Ran Wang ${ }^{\mathrm{a}}$ Aiju Lou \\ Dingji Zhu ${ }^{a}$ Guo-Ping Shib Min Yang ${ }^{a}$
}

aDepartment of Rheumatology and Immunology, Nanfang Hospital, Southern Medical University, Guangzhou, China; 'bepartment of Medicine, Brigham and Women's Hospital and Harvard Medical School, Boston, USA

\section{Key Words}

Rheumatoid arthritis • Circular RNAs • Microarray assay

\begin{abstract}
Background/Aims: Circular RNAs (circRNAs) compose a large class of RNAs that can be used as biomarkers in clinical blood samples. This study aimed to determine the expression of circRNAs in peripheral blood mononuclear cells (PBMCs) from rheumatoid arthritis (RA) patients to identify novel biomarkers for RA screening. Methods: We started with a microarray screening of circRNA changes in PBMCs from 5 RA patients and 5 healthy controls. We then confirmed the selected circRNA changes in PBMCs from 30 RA patients and 25 age- and sex-matched controls using the real-time quantitative reverse transcription-polymerase chain reaction (qRT-PCR). Spearman correlation test was performed to assess the correlation of circRNAs and clinical variables. Receiver operating characteristic (ROC) curve was calculated to evaluate the diagnostic value. Results: We identified and verified five circRNAs (092516, $003524,103047,104871,101873)$ that were significantly elevated in PBMCs from RA patients. Among these RA patients, we detected no significant correlation between the five circRNAs and the disease severity, including disease activity score (DAS28), erythrocyte sedimentation rate $(E S R), C$-reactive protein (CRP), and health assessment questionnaire (HAQ). Yet, ROC curve analysis suggested that circRNA_104871 has significant value of RA diagnosis (AUC $=0.833$, $\mathrm{P}<0.001$ ), followed by circRNA_003524 (AUC $=0.683, \mathrm{P}=0.020$ ), circRNA_101873 (AUC $=0.676$, $P=0.026)$, and circRNA_103047 (AUC $=0.671, P=0.030)$. Conclusions: This study suggests that increased expression of circRNAs circRNA_104871, circRNA_003524, circRNA_101873 and circRNA_103047 in PBMC from RA patients may serve as potential biomarkers for RA patient diagnosis.
\end{abstract}




\section{Cellular Physiology Cell Physiol Biochem 2017;42:651-659 \begin{tabular}{l|l} 
and Biochemistry Publ: 10.1159/000477883 & $\begin{array}{l}\text { (c) 2017 The Author(s). Published by S. Karger AG, Basel } \\
\text { www.karger.com/cpb }\end{array}$ \\
\hline
\end{tabular} Ouyang et al.: CircRNAs in PBMCs from RA Patients}

\section{Introduction}

Rheumatoid arthritis (RA) is a chronic disease characterized by autoimmunity and systemic inflammation with progressive impairment of the joints that leads to lifelong disability and increased mortality [1]. Early diagnosis and proper treatment can prevent severe disease manifestations in patients with RA. Despite advances in the treatment of RA in recent years, including the introduction of biologic therapies and the use of combination disease-modifying anti-rheumatic drug (DMARD) strategies, remission rates remain suboptimal [2]. It may be because the real cause of the disease is still unknown.

Circular RNAs (circRNAs), a unique class of endogenous RNAs, compose mainly of transcripts from the exons and are formed by non-colinear reverse splicing by covalently joining the 3'- and 5' -ends from the back-splice events. They are widely expressed in mammalian cells and play crucial roles in the regulation of gene expression at the transcriptional or post-transcriptional levels $[3,4]$ Compared with traditional linear RNA, circRNAs do not have the free $3^{\prime}$ or $5^{\prime}$ ends, but form covalently closed continuous loops $[5,6]$. This confers resistance to RNase R treatment, allowing circRNAs to be selectively enriched during sample processing and making them more suitable biomarkers than other types of RNA [7-9]. Studies demonstrated that circRNAs are involved in the development of several diseases, such as cancer [10-12], Alzheimer's disease [13], major depressive disorder [14], atherosclerotic vascular disease [15], and pre-eclampsia [16]. Recent studies have found that circRNAs can bind to microRNAs (miRNAs) and act as "miRNA sponges" by sequestering target miRNAs and preventing them from regulating other endogenous target genes. CircRNAs can also interact with RNA-binding proteins to regulate gene transcription $[17,18]$. For example, a recently identified miR-7 circRNA sponge contains more than 70 conserved miR-7 sites. This circRNA sponge strongly suppresses miR-7 activity and increases the expression of miR-7 target genes [18]. Although circRNAs are considered important biological molecules to understand gene regulation and associated disease pathogenesis, it is important but not tested whether these circRNAs may also serve as disease biomarkers for both diagnosis and medical treatment. Little is known about these RNAs in human RA.

This study was designed to determine whether circRNAs in PBMCs could be used as novel biomarkers for RA diagnosis. Altered changes of circRNAs may lead to the understanding of potential mechanisms of RA development and therapeutic strategy.

\section{Materials and Methods}

\section{Patient variables}

A total of 65 participants were recruited consecutively for this study: 35 patients with RA and 30 healthy controls. All RA patients were newly diagnosed at the Department of Rheumatology and Immunology at Nanfang Hospital of Southern Medical University between 2015 and 2016. Age and sex-matched healthy subjects who received a regular physical examination at the Department of Health from the same hospital were recruited as control subjects. All RA patients fulfilled the American College of Rheumatology criteria for the classification of RA [19]. Patients receiving any type of nonsteroidal anti-inflammatory drug, DMARD, glucocorticoid, immunesuppressor, or biological agent, or those with severe liver or kidney diseases, were excluded. All study protocols were approved by the ethics committee of Nanfang Hospital of Southern Medical University (NO.NFEC-2015-102). Written informed consent was obtained from all participants.

PBMC preparation and total RNA extraction

PBMCs from each donor were isolated using density centrifugation ( $400 \mathrm{~g}$ for $35 \mathrm{~min}$ ) of $8 \mathrm{~mL}$ of blood layered on $6 \mathrm{~mL}$ of $1.077 \mathrm{~g} / \mathrm{mL}$ Ficoll-Paque PLUS (GE Healthcare, Uppsala, Sweden) at $25^{\circ} \mathrm{C}$. The cells were frozen in Trizol (Invitrogen, Carlsbad, CA, USA) at a concentration of 5-7 $\times 10^{6} / \mathrm{ml}$ and stored at $-80^{\circ} \mathrm{C}$. Total RNA was extracted from PMBCs using Trizol reagent according to the manufacturer's instruction. The RNA quantity was measured with a NanoDrop ND-1000 (Agilent, Santa Clara, CA, USA) 


\begin{tabular}{|c|c|c|}
\hline Cellular Physiology & Cell Physiol Biochem 2017; & 22:651-659 \\
\hline and Rinchemictry & 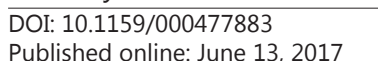 & $\begin{array}{l}\text { O } 2017 \text { The Author(s). Published by S. Karger AG, Basel } \\
\text { www.karger.com/cpb }\end{array}$ \\
\hline
\end{tabular}

Microarray hybridization

Sample labeling and array hybridization were performed according to the manufacturer's protocol (Arraystar Inc., Rockville, MD, USA). Briefly, total RNA was digested with RNase $\mathrm{R}$ (EpicentreInc., Madison, WI, USA) to remove linear RNAs and enrich circRNAs. The enriched circRNAs were amplified and transcribed into fluorescent circRNAs utilizing a random priming method (Arraystar Super RNA Labeling Kit, Arraystar Inc). The labeled circRNAs were hybridized to the Arraystar Human circRNA Microarray version $2.0 \quad$ (8 $\times 15 \mathrm{~K}$, Arraystar Inc). After washing the slides, the arrays were scanned with an Agilent Scanner G2505C. Agilent Feature Extraction software (version 11.0.1.1) was used to analyze the acquired array images. Quantile normalization and subsequent data processing were performed using the $\mathrm{R}$ software package ( $\mathrm{R}$ version 3.1 .2 ). The microarray work was performed by KangChen Bio-tech, Shanghai, China.

\section{Quantitative RT-PCR analysis}

cDNA was synthesized from total RNA using a Prime-Script RT reagent kit with gDNA Eraser (TaKaRa, Shiga, Japan). The primers used in qRT-PCR are shown in Table 1. $\beta$-actin was used as an internal control. The data were analyzed using the $2^{\wedge}-\Delta \Delta$ Ct method and presented as relative expression levels from three independent experiments.

\section{Statistical analysis}

The groups were compared to evaluate the statistical significance using the Mann-Whitney test, Student's t-test, Wilcoxon signed-rank test or Chi-square test, as appropriate. Associations between parameters were analyzed using the Spearman rank correlation. ROC curves were performed to evaluate the diagnostic value of circRNAs that were dysregulated in the PBMCs of RA patients compared to healthy controls. $P<0.05$ was considered as statistical significant. All statistical analyses were performed using SPSS version 16.0 (SPSS Inc., Chicago, IL).

\section{Results}

Circular RNA expression profiling in PBMCs from patients with RA

The baseline characteristics of all study participants are presented in Table 2 . To identify circRNAs that were differentially expressed in RA, we performed microarray analysis with circRNAs in the PBMCs from 5 patients with RA and 5 age- and sex-matched healthy controls using an Arraystar Human circRNA Microarray version 2.0. After normalization of the raw data, we identified 12 circRNAs that were differentially expressed between the two
Table 1. Specific circRNA primers used for quantitative RT-PCR analysis

\begin{tabular}{|c|c|c|}
\hline Name & Sequence & Product size (bp) \\
\hline$\beta$-actin & $\begin{array}{l}\text { F: 5'-GTGGCCGAGGACT'TTGATTG-3' } \\
\text { R: 5'-CCTGTAACAACGCATCTCATATT-3' }\end{array}$ & 73 \\
\hline hsa_circRNA_103047 & $\begin{array}{l}\text { F: 5'-CACTGACTTGCCACTCCTTTG-3' } \\
\text { R: 5'-GTCTGTTAGGTGGATGCTTTGT-3' }\end{array}$ & 195 \\
\hline hsa_circRNA_080802 & $\begin{array}{l}\text { F: 5'-GGTGACTGTGGCACTCCAAGC-3' } \\
\text { R: 5'-GACCTTCAGGTGGCAGGTGAT-3' }\end{array}$ & 115 \\
\hline hsa_circRNA_003524 & $\begin{array}{l}\text { F: 5'-TCCTGGAGCGAATCCTACCTT-3' } \\
\text { R: 5'-TTTGGCATTTGCATAGGGAAC-3' }\end{array}$ & 94 \\
\hline hsa_circRNA_092516 & $\begin{array}{l}\text { F: 5'-GT"TCCT"IACCAGCCTCCCT"I"l-3' } \\
\text { R: 5'-TGAAGAGTCAATACCGCCAGA-3' }\end{array}$ & 75 \\
\hline hsa_circRNA_407202 & $\begin{array}{l}\text { F: 5'-GCACTATGCTCCTTTCCTCTTG-3' } \\
\text { R: 5'-AAATTGAACACCACTACTACCGC-3' }\end{array}$ & 63 \\
\hline hsa_circRNA_405718 & $\begin{array}{l}\text { F: 5'-TGCGGAGGGACGATGATGAG-3' } \\
\text { R: 5'-CGACCACCACTACCCGTGTATGT-3' }\end{array}$ & 121 \\
\hline hsa_circRNA_104871 & $\begin{array}{l}\text { F: 5'-CGGAACTTCCTGTGGTCATCT-3' } \\
\text { R: 5'-TCCATCTCAAGCAGGTTTCATT-3' }\end{array}$ & 96 \\
\hline hsa_circRNA_405527 & $\begin{array}{l}\text { F: 5'-AACACCAACGTGGGCATCAT-3' } \\
\text { R: 5'-GGAGTCATTCTTCCCGTCTTCA-3' }\end{array}$ & 126 \\
\hline hsa_circRNA_101873 & $\begin{array}{l}\text { F: 5'-TACTTCATACTGCTTGTGCCC-3' } \\
\text { R: 5'-CACATAGACTGGAGATGACGC-3' }\end{array}$ & 85 \\
\hline hsa_circRNA_090069 & 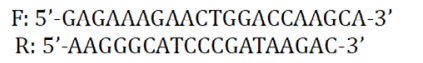 & 93 \\
\hline
\end{tabular}


Table 2. Clinical characters and laboratory measures of the participants. Abbreviations: RA: rheumatoid arthritis; M/F: male/ female; ESR: erythrocyte sedimentation rate; CRP: C-reactive protein; HAQ: health assessment questionnaire; DAS28: disease activity score in 28 joints; RF: rheumatoid factor; anti-CCP: anti-cyclic citrullinated peptide antibodies; NA: not available. Data are expressed as median (range)

\begin{tabular}{lllll}
\hline & \multicolumn{2}{c}{ Micrnarray analysis } & \multicolumn{2}{l}{ Validation } \\
& RA & Control & RA & Control \\
& $(\mathrm{n}=5)$ & $(\mathrm{n}=5)$ & $(\mathrm{n}=30)$ & $(\mathrm{n}=25)$ \\
\hline Age (years) & $45(35-65)$ & $48(32-68)$ & $52(17-71)$ & $49(30-66)$ \\
Sex (M/F) (n) & $2 / 3$ & $2 / 3$ & $9 / 21$ & $7 / 18$ \\
ESR (mm/h) & $59(41-95)$ & $\mathrm{NA}$ & $38.5(9-112)$ & $\mathrm{NA}$ \\
CRP (mg/l) & $65.2(25.3-91.1)$ & $\mathrm{NA}$ & $16.8(0.34-107.3)$ & $\mathrm{NA}$ \\
Anti-CCP $(\mathrm{U} / \mathrm{ml})$ & $83.4(30.1-450)$ & $\mathrm{NA}$ & $151.1(7.8-1200)$ & $\mathrm{NA}$ \\
HAQ (scores) & $1.15(0.5-2)$ & $\mathrm{NA}$ & $1.06(0-2.0)$ & $\mathrm{NA}$ \\
DAS28 (scores) & $5.74(5.08-7.25)$ & $\mathrm{NA}$ & $5.86(3.08-8.16)$ & $\mathrm{NA}$ \\
IgM RF $(\mathrm{IU} / \mathrm{ml})$ & $98.8(60-411)$ & $\mathrm{NA}$ & $164(9.19-4700)$ & $\mathrm{NA}$ \\
Lymphocyte $\left(10^{9} / \mathrm{L}\right)$ & $1.55(1.13-2.50)$ & $1.67(1.16-2.80)$ & $1.68(1.12-2.88)$ & $1.88(1.22-3.1)$ \\
Monocyte $\left(10^{9} / \mathrm{L}\right)$ & $0.36(0.13-0.48)$ & $0.32(0.15-0.50)$ & $0.32(0.12-0.51)$ & $0.34(0.18-0.56)$ \\
\hline
\end{tabular}

Table 3. Microarray analysis of circRNAs that are up- or down-regulated in 5 RA patients compared with 5 healthy controls

\begin{tabular}{llllll}
\hline circRNAs & $P$ & Fold change & Regulation & circRNA type & Gene symbol \\
hsa_circRNA_101873 & 0.044 & 1.760 & Up & Exonic & GLG1 \\
hsa_circRNA_080802 & 0.043 & 2.129 & Up & Exonic & ZP3 \\
hsa_circRNA_405527 & 0.025 & 1.542 & Up & Exonic & TRPV1 \\
hsa_circRNA_103047 & 0.012 & 1.614 & Up & Exonic & PHF20 \\
hsa_circRNA_090069 & 0.044 & 1.552 & Up & Exonic & PHEX \\
hsa_circRNA_003524 & 0.007 & 1.531 & Up & Exonic & FAM168B \\
hsa_circRNA_080731 & 0.020 & 1.859 & Up & Exonic & HIP1 \\
hsa_circRNA_104871 & 0.037 & 1.536 & Up & Exonic & SUSD1 \\
hsa_circRNA_092516 & $<0.001$ & 1.639 & Up & Sense overlapping & XBP1 \\
hsa_circRNA_405718 & 0.034 & 2.363 & Down & Exonic & UHRF1 \\
hsa_circRNA_000905 & 0.043 & 1.689 & Down & Antisense & SULF2 \\
hsa_circRNA_407202 & 0.027 & 2.368 & Down & Exonic & PTCH1 \\
\hline
\end{tabular}

populations by screening for $\log 2$ fold-changes greater than 1.5 (Fig. 1A) and $P<0.05$ (Fig. 1B). Compared with healthy controls, we found that 9 circRNAs were up-regulated and 3 were down-regulated in patients with RA (Table 3). A heat map was created to group the circRNAs based on their expression levels among the samples (Fig. 1C).

Quantitative RT-PCR validation of differentially expressed circRNAs

To validate the microarray expression data, we selected 10 dysregulated circRNAs, including 8 up-regulated circRNAs (092516, 003524, 103047, 405527,104871, 080802, 101873, 090069) and 2 down-regulated circRNAs (407202, 405718) (Table 3, Fig. 1C) for further assessment based on their P values $(<0.05)$, fold changes $(>1.5)$ and their raw intensities ( $>100$ ). Quantitative RT-PCR was performed to validate the 10 candidate circRNAs using an independent set of samples from 30 RA patients and 25 healthy controls. Consistent with the microarray data, the average expression levels of circRNA_092516, circRNA_003524, circRNA_103047, circRNA_104871, and circRNA_101873 in the PBMCs of patients with RA were significantly higher than those of the healthy controls, while the expression of circRNA_080802, circRNA_090069, and circRNA_407202 did not show any remarkable differences between patients with RA and the healthy controls (Fig. 2). The expression levels of circRNA_405718 and circRNA_405527 were not detectable in the PBMCs from RA patients or healthy controls.

Spearman correlation test of clinical variables and confirmed circRNAs in PBMCs from RA patients

To determine whether the significantly and differentially expressed circRNAs in the PBMCs from RA patients were relevant biomarkers for the severity of RA, we performed the Spearman correlation test to assess the correlation between RA-related clinical features and 
Fig. 1. Microarray determined the circRNA expression profiles in 5 RA patients and 5 healthy controls (Normal). A. CircRNA Scatter-Plot. Dots above the top green line and below the bottom green line indicate greater than 1.5-fold of changes of logarithmized circRNAs between the two compared groups. B. CircRNAs (red point) in the Volcano Plots represents the 1.5 -fold up- and down-regulated logarithmized circRNAs with statistical significance $(P<0.05)$. C. Heat map of differentially expressed circRNAs. 'Red' indicates high relative expression, and 'green' indicates low relative expression.
A

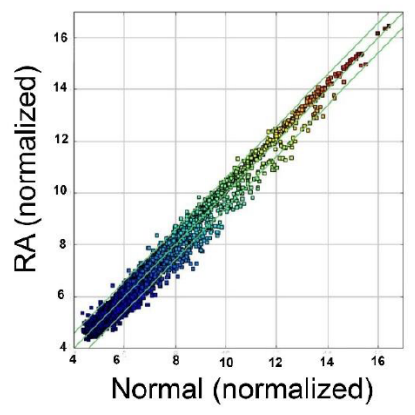

B

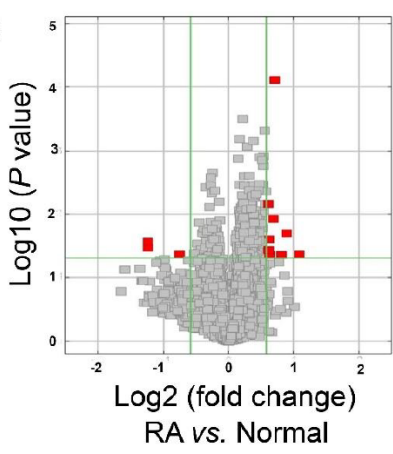

C

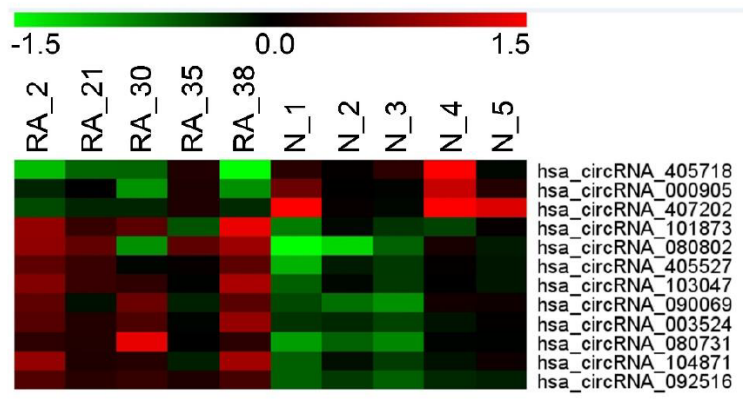

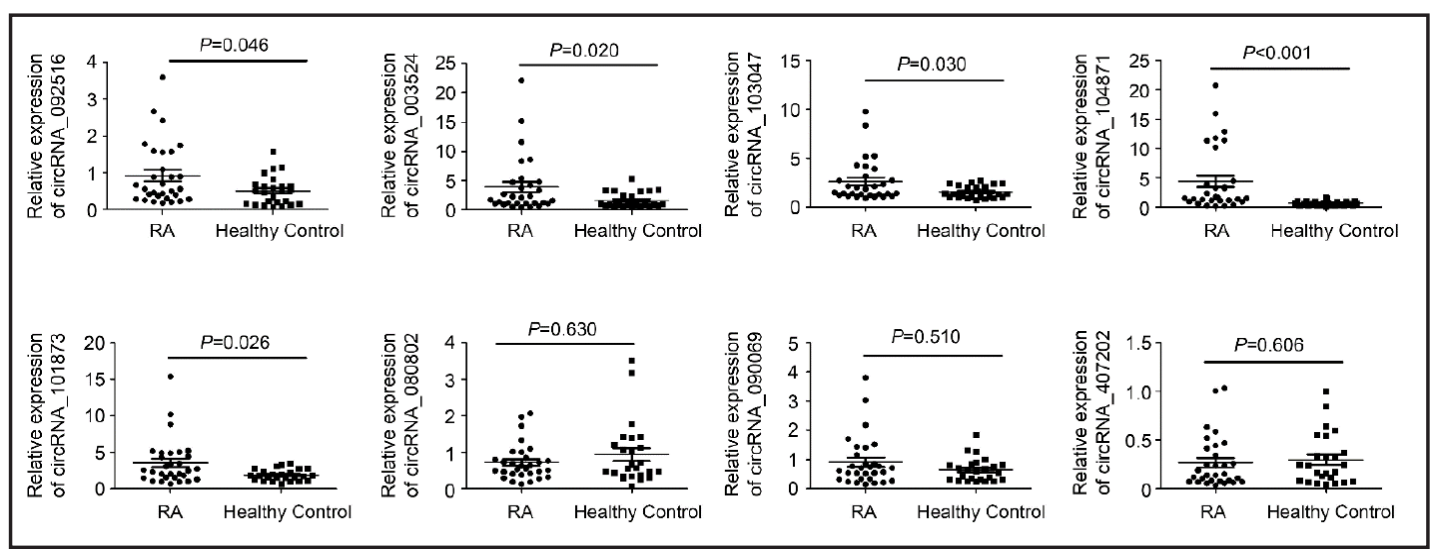

Fig. 2. Quantitative RT-PCR determined the relative expression levels of circRNAs in PBMCs from 30 RA patients and 25 healthy controls. The probability values were calculated using the Mann-Whitney test or Student's t-test, depending on data distributions, based on the comparisons with the RA and healthy control groups.

circRNA_092516, circRNA_003524, circRNA_103047,circRNA_104871, and circRNA_101873 in the PBMCs from RA patients. As shown in Table 4, the levels of all confirmed circRNAs in the PBMCs from RA patients did not correlate with DAS28, CRP, ESR or HAQ, which reflect the severity of the disease. However, they did correlate with each other. For example, the level of circRNA_003524 correlated with the level of circRNA_103047 ( $\mathrm{r}=0.824, P<0.01)$.

ROC curve analysis of confirmed PMBC circRNAs among RA patients

To assess the potential value of significantly and differentially expressed circRNAs for RA diagnosis, we performed ROC curve analysis. ROC curves of confirmed circRNAs showed that the levels of circRNA_104871, circRNA_003524, circRNA_101873, and circRNA_103047 in PBMCs could separate the patients with RA from the healthy controls. The highest AUC was found for circRNA_104871 (AUC: 0.833, 95\% CI 0.721-0.944, $P<0.001$ ), followed by 


\section{Cellular Physiology Cell Physiol Biochem 2017;42:651-659 \begin{tabular}{l|l} 
and Biochemistry Published online: June 13, 2017 & $\begin{array}{l}\text { (C) } 2017 \text { The Author(s). Published by S. Karger AG, Basel } \\
\text { www.karger.com/cpb }\end{array}$
\end{tabular}

Table 4. Spearman rank correlation coefficients of clinical variables and quantitative RT-PCR-confirmed circRNAs in PBMCs from RA patients. Abbreviations: ESR: erythrocyte sedimentation rate; CRP: C-reactive protein; HAQ: health assessment questionnaire; DAS28: disease activity score in 28 joints; RF: rheumatoid factor; anti-CCP: anti-cyclic citrullinated peptide antibodies. ${ }^{*} P<0.05,{ }^{* *} P<0.01$

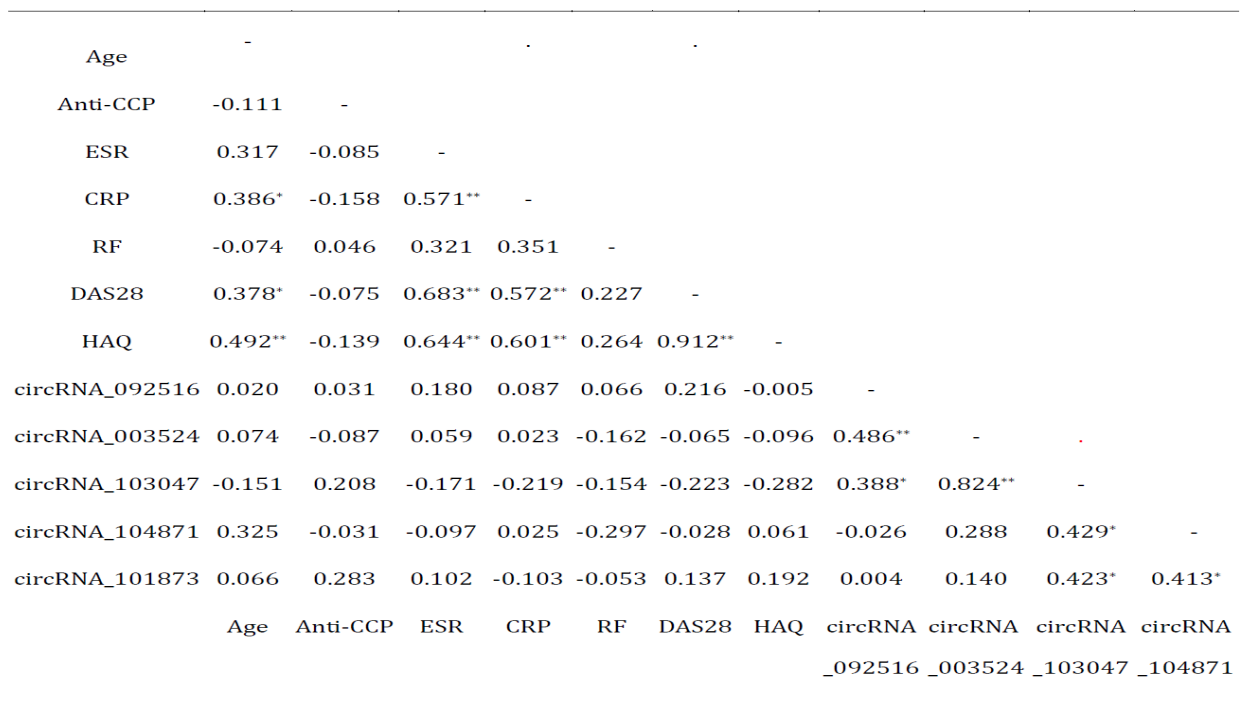

Fig. 3. ROC analysis of confirmed circRNAs in PBMCs from RA patients. The largest AUC was found for circRNA_104871 (AUC: 0.833), followed by circRNA_003524 (AUC: 0.683), circRNA_101873 (AUC: 0.676), and circRNA_103047(AUC: 0.671).

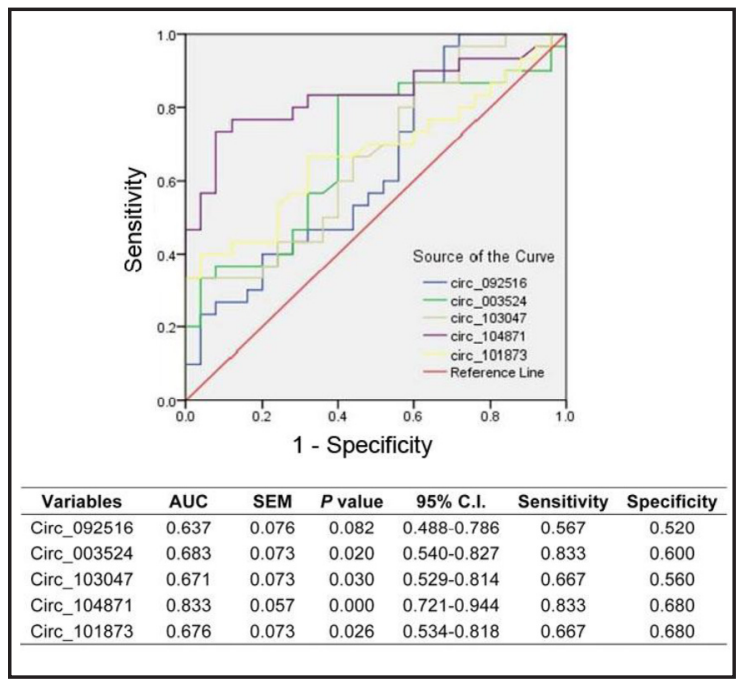

circRNA_003524 (AUC: $0.683,95 \%$ CI 0.54-0.827, $P=0.020$ ), circRNA_101873 (AUC: 0.676, 95\% CI 0.534-0.818, $P=0.026$ ), and circRNA_103047 (AUC: 0.671, 95\% CI 0.529-0.814, $P=$ 0.030 ; Fig. 3). Therefore, circRNA_104871 may be more useful than the other 3 circRNAs as a biomarker for RA diagnosis. Combined AUC from these circRNAs was increased slightly, but was close to the value of individual AUC. For example, combined AUC for both circRNA_104871 and circRNA_003524 was $0.855(P<0.05)$, similar to that of circRNA_104871 (AUC $=0.833$ ).

\section{Discussion}

CircRNAs are widely expressed in human cells, and their expression levels can be 10fold or greater than those of their linear isomers [20]. Compared with miRNAs and long noncoding RNAs (lncRNAs), circRNAs are more stable in mammalian cells [21]. These properties give circRNAs the potential of being ideal biomarkers for human diseases. Recent 


\section{Cellular Physiology Cell Physiol Biochem 2017;42:651-659

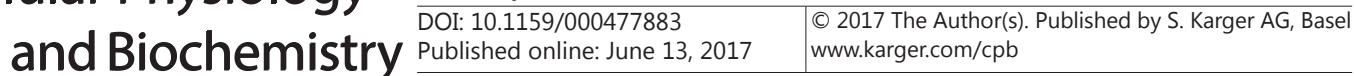 \\ Ouyang et al.: CircRNAs in PBMCs from RA Patients}

studies have revealed that circRNAs can be used as diagnostic or predictive biomarkers for hepatocellular carcinoma [11], pre-eclampsia [22], gastric cancer [23], and bladder cancer [24]. However, little is known about the role of circRNAs in RA. In this study, we performed a microarray analysis of dysregulated circRNAs by comparing the transcriptome profiles of PBMCs from patients with RA and those from healthy controls. A total of 12 significantly and differentially expressed circRNAs were detected, with 9 circRNAs up-regulated and 3 downregulated. These observations may assist future pathophysiology researches in RA and help determine whether circRNAs in PBMCs could be used as novel, non-invasive biomarkers for RA diagnosis and treatment. PBMCs compose mainly lymphocytes and monocytes. We compared the numbers of monocytes and lymphocytes between the RA and healthy control groups, and we found no significant difference $(P>0.05$, Table 2$)$, suggesting that the differences in circRNA expression from PBMCs between the RA and healthy control groups were not because of lymphocyte or monocyte number differences.

CircRNA microarray profiling and qRT-PCR validation identified circRNA_092516, circRNA_003524, circRNA_103047, circRNA_104871, and circRNA_101873 significantly and differentially expressed in the PBMCs of RA patients compared with those from healthy controls. These results indicate that the altered expression of circRNAs may be related to their involvement in the pathogenesis of RA. Furthermore, our study found that the expression of all confirmed circRNAs in the PBMCs of RA patients was not correlated with DAS28, CRP, ESR or HAQ, indicating that these circRNAs may not be relevant biomarkers for disease severity or systemic inflammation in RA. However, we found that the levels of some confirmed circRNAs correlated with each other; for example, the level of circRNA_003524 correlated with the level of circRNA_103047 ( $\mathrm{r}=0.824, P<0.01)$. Therefore, we speculate that these circRNAs may interact with each other directly or indirectly, although further experiments are needed to test this possibility. In addition, in this study, we found that the levels of circRNA_104871, circRNA_003524, circRNA_101873, and circRNA_103047 in PBMCs have potential diagnostic value for RA. This was especially true for circRNA_104871, which showed a highest ROC AUC value among all others, indicating its high potential as a diagnostic biomarker.

There are however some limitations in the present study. First is the relatively small sample size; these data may be confirmed in large-scale studies and in other populations with different races or from different regions. Second, to determine whether circRNA_104871 can be a diagnostic biomarker, it should be evaluated for its ability to effectively distinguish RA from other rheumatic diseases, such as systemic lupus erythematosus (SLE), osteoarthritis $(\mathrm{OA})$, and ankylosing spondylitis (AS), which are also characterized by joint damage. These other rheumatic diseases should be included in further studies to strengthen the contention that circRNA_104871 may serve as a diagnostic biomarker for RA. Third, we did not analyze circRNAs in the plasma or serum. Studies have shown that exonic circRNA is not stable in the serum, with a half-life of less than $15 \mathrm{~s}$ [18], and that circRNAs compose only a small percentage of the total RNA.

\section{Conclusions}

Our study is the first to measure circRNA expression in PBMCs from RA patients and from healthy controls. Our findings might enhance our knowledge regarding the role of circRNAs in RA. In addition, we found that circRNAs may have value in RA diagnosis. These observations should have potential clinical significance, and may help understand the molecular mechanisms and biological functions of circRNAs in RA, all which merit further investigation.

\section{Acknowledgements}

The authors thank the donors who provided their blood samples. This study was supported by the National Natural Science Fund of China (No. 81172875 to MY) and award from the Lupus Research Alliance (No. 519416 to GPS).

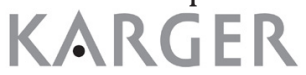




\section{Cellular Physiology Cell Physiol Biochem 2017;42:651-659 \begin{tabular}{l|l} 
DOI: 10.1159/000477883 & and Biochemistry 2017 The Author(s). Published by S. Karger AG, Basel \\
Published online: June 13, 2017 & $\begin{array}{l}\text { www.karger.com/cpb } \\
\text { Ond }\end{array}$
\end{tabular} Ouyang et al.: CircRNAs in PBMCs from RA Patients}

\section{Disclosure Statement}

The authors declare no conflicts of interest.

\section{References}

-1 Murata K, Furu M, Yoshitomi H, Ishikawa M, Shibuya H, Hashimoto M, Imura Y, Fujii T, Ito H, Mimori T, Matsuda S: Comprehensive microRNA analysis identifies miR-24 and miR-125a-5p as plasma biomarkers for rheumatoid arthritis. PLoS One 2013;8:e69118.

-2 Chen SY, Hsu WT, Chen YL, Chien CH, Chiang BL: Lymphocyte-activation gene 3(+) (LAG3(+)) forkhead box protein 3(-) (FOXP3(-)) regulatory T cells induced by B cells alleviates joint inflammation in collageninduced arthritis. J Autoimmun 2016;68:75-85.

-3 Memczak S, Jens M, Elefsinioti A, Torti F, Krueger J, Rybak A, Maier L, Mackowiak SD, Gregersen LH, Munschauer M, Loewer A, Ziebold U, Landthaler M, Kocks C, le Noble F, Rajewsky N: Circular RNAs are a large class of animal RNAs with regulatory potency. Nature 2013;495:333-338.

4 Capel B, Swain A, Nicolis S, Hacker A, Walter M, Koopman P, Goodfellow P, Lovell-Badge R: Circular transcripts of the testis-determining gene Sry in adult mouse testis. Cell 1993;73:1019-1030.

5 Qu S, Yang X, Li X, Wang J, Gao Y, Shang R, Sun W, Dou K, Li H: Circular RNA: A new star of noncoding RNAs. Cancer Lett 2015;365:141-148.

6 Chen LL, Yang L: Regulation of circRNA biogenesis. RNA Biol 2015;12:381-388.

7 Salzman J, Chen RE, Olsen MN, Wang PL, Brown PO: Cell-type specific features of circular RNA expression. PLoS Genet 2013;9:e1003777.

8 Rybak-Wolf A, Stottmeister C, Glazar P, Jens M, Pino N, Giusti S, Hanan M, Behm M, Bartok O, Ashwal-Fluss R, Herzog M, Schreyer L, Papavasileiou P, Ivanov A, Ohman M, Refojo D, Kadener S, Rajewsky N: Circular RNAs in the mammalian brain are highly abundant, conserved, and dynamically expressed. Mol Cell 2015;58:870-885.

9 Szabo L, Morey R, Palpant NJ, Wang PL, Afari N, Jiang C, Parast MM, Murry CE, Laurent LC, Salzman J: Statistically based splicing detection reveals neural enrichment and tissue-specific induction of circular RNA during human fetal development. Genome Biol 2015;16:126.

10 Xie H, Ren X, Xin S, Lan X, Lu G, Lin Y, Yang S, Zeng Z, Liao W, Ding YQ, Liang L: Emerging roles of circRNA_001569 targeting miR-145 in the proliferation and invasion of colorectal cancer. Oncotarget 2016;7:26680-26691.

11 Shang X, Li G, Liu H, Li T, Liu J, Zhao Q, Wang C: Comprehensive Circular RNA Profiling Reveals that hsa_circ_0005075, a New Circular RNA Biomarker, is Involved in Hepatocellular Crcinoma Development. Medicine 2016;95:e3811.

12 Li H, Hao X, Wang H, Liu Z, He Y, Pu M, Zhang H, Yu H, Duan J, Qu S: Circular RNA expression profile of pancreatic ductal adenocarcinoma revealed by microarray. Cell Physiol Biochem 2016;40:1334-1344. Lukiw WJ: Circular RNA (circRNA) in Alzheimer's disease (AD). Front Genet 2013;4:307. Cui X, Niu W, Kong L, He M, Jiang K, Chen S, Zhong A, Li W, Lu J, Zhang L: Hsa_circRNA_103636: Potential novel diagnostic and therapeutic biomarker in Major depressive disorder. Biomark Med 2016;10:943-952.

-15 Wu HJ, Zhang CY, Zhang S, Chang M, Wang HY: Microarray expression profile of circular RNAs in heart tissue of mice with myocardial Infarction-Induced heart failure. Cell Physiol Biochem 2016;39:205-216.

16 Qian Y, Lu Y, Rui C, Qian Y, Cai M, Jia R: Potential significance of circular RNA in human placental tissue for patients with preeclampsia. Cell Physiol Biochem 2016;39:1380-1390.

17 Hansen TB, Jensen TI, Clausen BH, Bramsen JB, Finsen B, Damgaard CK, Kjems J: Natural RNA circles function as efficient microRNA sponges. Nature 2013;495:384-388.

18 Jeck WR, Sharpless NE: Detecting and characterizing circular RNAs. Nat Biotechnol 2014;32:453-461.

19 Aletaha D, Neogi T, Silman AJ, Funovits J, Felson DT, Bingham CR, Birnbaum NS, Burmester GR, Bykerk VP, Cohen MD, Combe B, Costenbader KH, Dougados M, Emery P, Ferraccioli G, Hazes JM, Hobbs K, Huizinga TW, Kavanaugh A, Kay J, Kvien TK, Laing T, Mease P, Menard HA, Moreland LW, Naden RL, Pincus T, Smolen JS, Stanislawska-Biernat E, Symmons D, Tak PP, Upchurch KS, Vencovsky J, Wolfe F, Hawker G: 2010 rheumatoid arthritis classification criteria: An American College of Rheumatology/European League Against Rheumatism collaborative initiative. Ann Rheum Dis 2010;69:1580-1588. 


\section{Cellular Physiology Cell Physiol Biochem 2017;42:651-659}

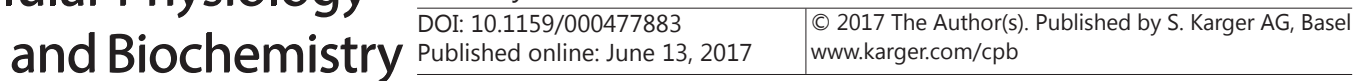

Ouyang et al.: CircRNAs in PBMCs from RA Patients

20 Jeck WR, Sorrentino JA, Wang K, Slevin MK, Burd CE, Liu J, Marzluff WF, Sharpless NE: Circular RNAs are abundant, conserved, and associated with ALU repeats. RNA 2013;19:141-157.

21 Liang D, Wilusz JE: Short intronic repeat sequences facilitate circular RNA production. Genes Dev 2014;28:2233-2247.

22 Zhang YG, Yang HL, Long Y, Li WL: Circular RNA in blood corpuscles combined with plasma protein factor for early prediction of pre-eclampsia. BJOG 2016;123:2113-2118.

23 Li P, Chen S, Chen H, Mo X, Li T, Shao Y, Xiao B, Guo J: Using circular RNA as a novel type of biomarker in the screening of gastric cancer. Clin Chim Acta 2015;444:132-136.

-24 Zhong Z, Lv M, Chen J: Screening differential circular RNA expression profiles reveals the regulatory role of circTCF25-miR-103a-3p/miR-107-CDK6 pathway in bladder carcinoma. Sci Rep 2016;6:30919. 